\title{
Experimental Investigation on Reliability of Variation Process of Rolling Bearing Vibration Performance
}

\author{
Xintao Xia ${ }^{a}$, Liang $\mathrm{Ye}^{\mathrm{b}^{*}}$ and Zhen Chang $^{\mathrm{c}}$ \\ School of Mechatronical Engineering, Henan University of Science and Technology, Luoyang \\ 471003, China \\ axiaxt1957@163.com, ${ }^{\mathrm{b}} 172682823 @ q q . c o m,{ }^{c}$ zhenc1992@163.com
}

\begin{abstract}
Keywords: Reliability; Variation process; Maximum entropy grey bootstrap principle; Reliability function; Variation probability
\end{abstract}

\begin{abstract}
The experimental investigation is conducted by collecting the vibration acceleration data of rolling bearings without any prior information on possibility distribution. The rolling bearing (type SKF6205) is used as an example to illustrate the application of maximum entropy grey bootstrap principle in analyzing the variation process. Monte Carlo method is applied to simulate the vibration acceleration data for different wear diameters. The upper and lower bound and estimated true value of reliability functions are achieved when the confidence level $P=0.95$. Then the variation probabilities can be calculated for different time series. The experimental investigation shows that the variation probabilities increase with the increase of wear diameters. Moreover, the variation probability presents a nonlinear increase trend, which can be divided into three stages: from the rapid increase stage to the slowly increase stage with trace fluctuations, and then to the rapid increase stage. The variation probability $P_{n}>0.8$ when the wear diameter $D=0.75 \mathrm{~mm}$ and confidence level $P=0.95$, which shows that the variation is serious for the vibration performance of bearings. So the rolling bearings should be maintained or replaced to avoid the occurrence of serious accidents.
\end{abstract}

\section{Introduction}

Reliability is the ability of products to perform its specified functions under the stated conditions for a given period, which can change the fuzzy qualitative concept on reliability into clear quantitative indicator throughout the design, manufacture and inspection process of products. The performance reliability of rolling bearings is the possibility that rolling bearings realize the demand of work host during the experiment [1-3]. Moreover, the performance reliability of bearings changes with time. Therefore, it is necessary for studying the reliability variation process during the service period of bearings [4-6].

In view of this, the maximum entropy grey bootstrap principle $[7,8]$ is applied to obtain the estimated true value function and the functions of upper and lower bounds of reliability, which belongs to the poor information theory [9-11]. Then the experiment is conducted to analyze he variation process of vibration performance reliability of rolling bearings. The variation probabilities are calculated under different wear diameters so some intervention measures can be taken before vibration performance of bearings fails.

\section{Experimental Investigation}

Four data sequences of vibration acceleration of rolling bearings (type SKF6205) is collected to analyze the variation process when the wear diameters are $0 \mathrm{~mm}, 0.1778 \mathrm{~mm}, 0.5334 \mathrm{~mm}$ and $0.7112 \mathrm{~mm}$ [7]. Then the standard deviation values of the data sequences are obtained for different time series as shown in Fig. 1.

The standard deviation values can be achieved as shown in Table 1 when wear diameters $D$ are from $0 \mathrm{~mm}$ to $0.75 \mathrm{~mm}$.

Taking the vibration acceleration sequence as an example when $S=0.15 \mathrm{~mm}$, which is considered to be the second time sequence, Monte Carlo method is used to simulate 1600 data. Then the data is 
divided into 4 groups to calculate the variation number and variation frequency of the time sequence [8]. The results are shown in Table 2.

Table 1 The standard deviation values of of 7 time sequences

\begin{tabular}{ccc}
\hline Sequence number & Wear diameter & $\begin{array}{c}\text { Standard deviation } \\
\text { D/mm }\end{array}$ \\
$n$ & 0 & 0.05975 \\
1 & 0.15 & 0.257 \\
2 & 0.3 & 0.362 \\
3 & 0.45 & 0.424 \\
4 & 0.6 & 0.583 \\
5 & 0.75 & 0.819 \\
6 & &
\end{tabular}

Table 2 The variation number and variation frequency of the sub sequences

\begin{tabular}{ccc}
$\begin{array}{c}\text { Sub sequence } \\
\text { number }\end{array}$ & $\begin{array}{c}\text { Variation } \\
\text { number } \\
d\end{array}$ & $\begin{array}{c}\text { Variation } \\
\text { frequency }\end{array}$ \\
$N_{2 d}$ & $\lambda_{2 d}$ \\
2 & 772 & 0.4825 \\
3 & 992 & 0.6200 \\
4 & 748 & 0.4675 \\
\hline
\end{tabular}

10000 re-sampling data is obtained with grey bootstrap method as shown in Fig. 2.

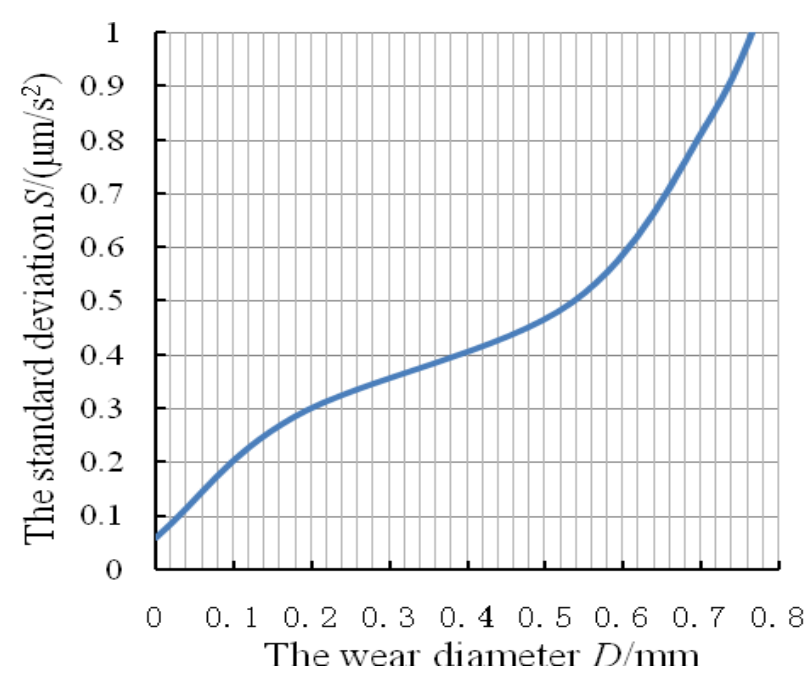

Figure 1. The standard deviations values of time series

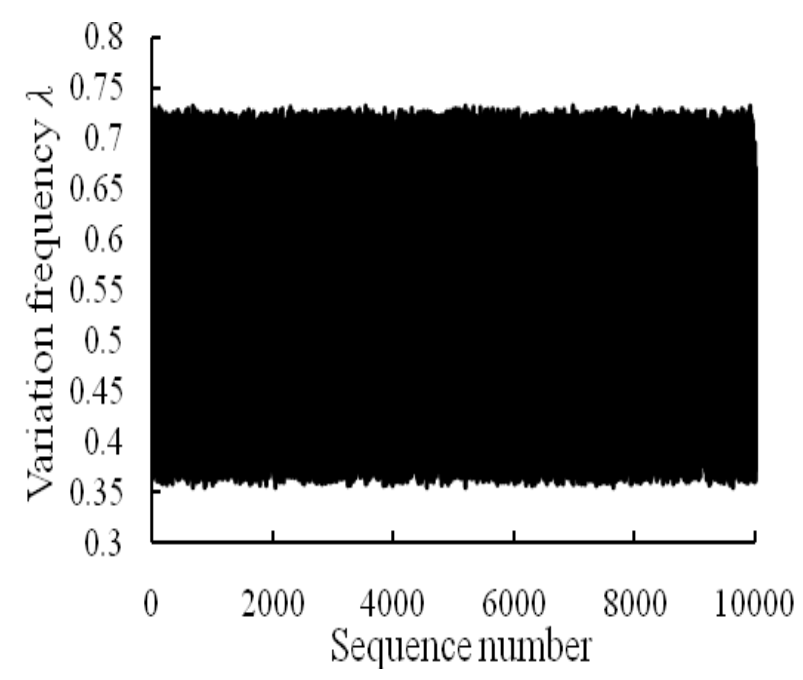

Figure 2. 10000 re-sampling data

The maximum entropy principle is used to obtain the probability density function of time series. The function is shown in Fig. 3. 
Suppose that the significant level $\alpha$ is 0.05 , the estimated value $\lambda_{20}$ is 0.5254 and the confidence interval $\left[\lambda_{2 \mathrm{~L}}, \lambda_{2 \mathrm{U}}\right]$ is $[0.3599,0.6212]$ when $P=95 \%$. The estimated true value function $R_{2}$ and the reliability functions of its upper and lower bounds $R_{3}$ and $R_{1}$ are shown in Fig. 4.

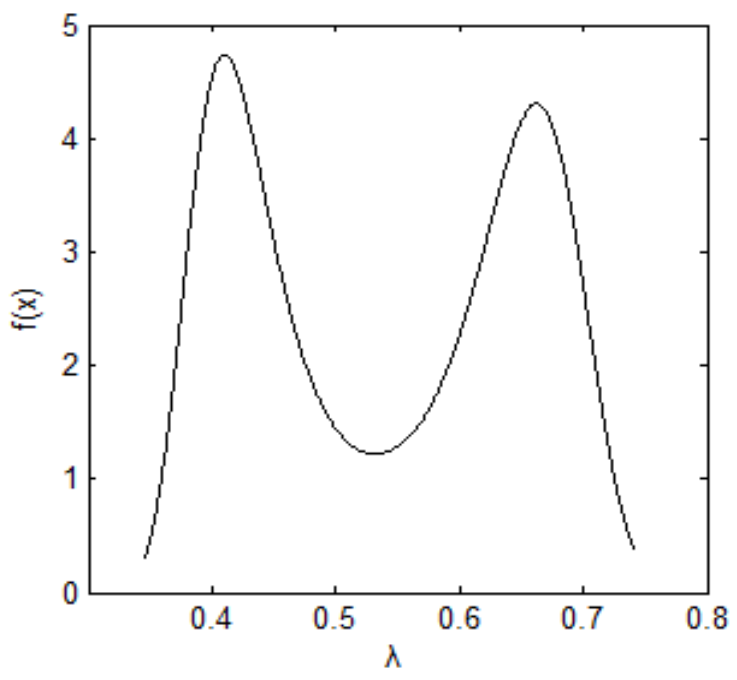

Figure 3. The probability density function

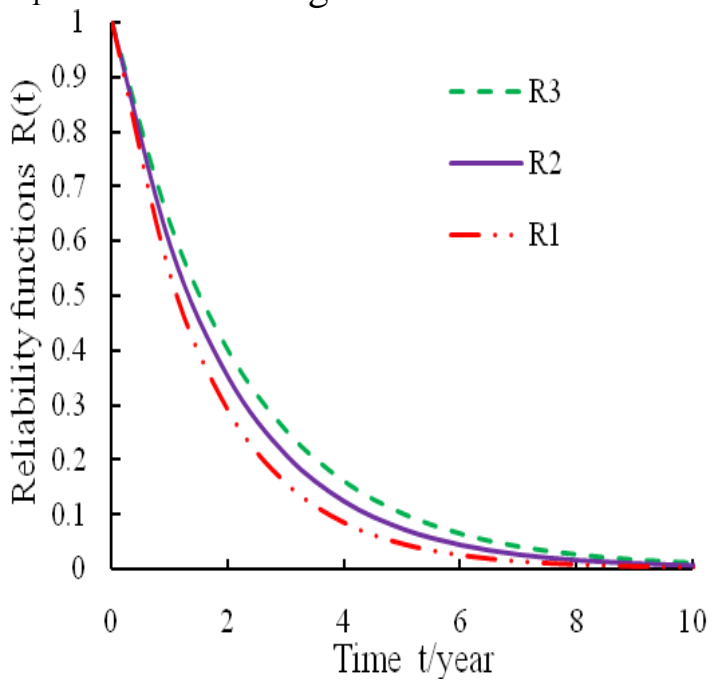

Figure 4. The reliability functions of vibration performance of rolling bearings

Likewise, the estimated values $\lambda_{n 0}$ and the confidence intervals $\left[\lambda_{n} \mathrm{~L}, \lambda_{n \mathrm{U}}\right]$ are obtained for 7 time sequences as shown in Table 3 .

Table 3 The estimated values and the confidence intervals of 7 time sequences

\begin{tabular}{|c|c|c|c|c|}
\hline $\begin{array}{c}\text { Time } \\
\text { sequence }\end{array}$ & $\begin{array}{c}\text { Wear } \\
\text { diameter }\end{array}$ & $\begin{array}{l}\text { Estimated } \\
\text { value }\end{array}$ & $\begin{array}{c}\text { Lower bound } \\
\text { value }\end{array}$ & $\begin{array}{c}\text { Upper bound } \\
\text { value }\end{array}$ \\
\hline$n$ & $\mathrm{D} / \mathrm{mm}$ & $\lambda_{n 0}$ & $\lambda_{n \mathrm{~L}}$ & $\lambda_{n \mathrm{U}}$ \\
\hline 1 & 0 & 0.04875 & -0.1114 & 0.1235 \\
\hline 2 & 0.15 & 0.5254 & 0.3599 & 0.6212 \\
\hline 3 & 0.3 & 0.6412 & 0.4689 & 0.7401 \\
\hline 4 & 0.45 & 0.6794 & 0.5587 & 0.7122 \\
\hline 5 & 0.6 & 0.7478 & 0.6235 & 0.8873 \\
\hline 6 & 0.75 & 0.9219 & 0.8396 & 0.9844 \\
\hline
\end{tabular}

The probability density functions are obtained for time sequences in the reliability variation process as shown in Fig. 5.

The abscissas values $t_{n}$ can be calculated for the intersection points of probability density functions of sub sequences and the intrinsic sequence. Then the overlapped areas and variation probabilities are obtained as shown in Table 4. 


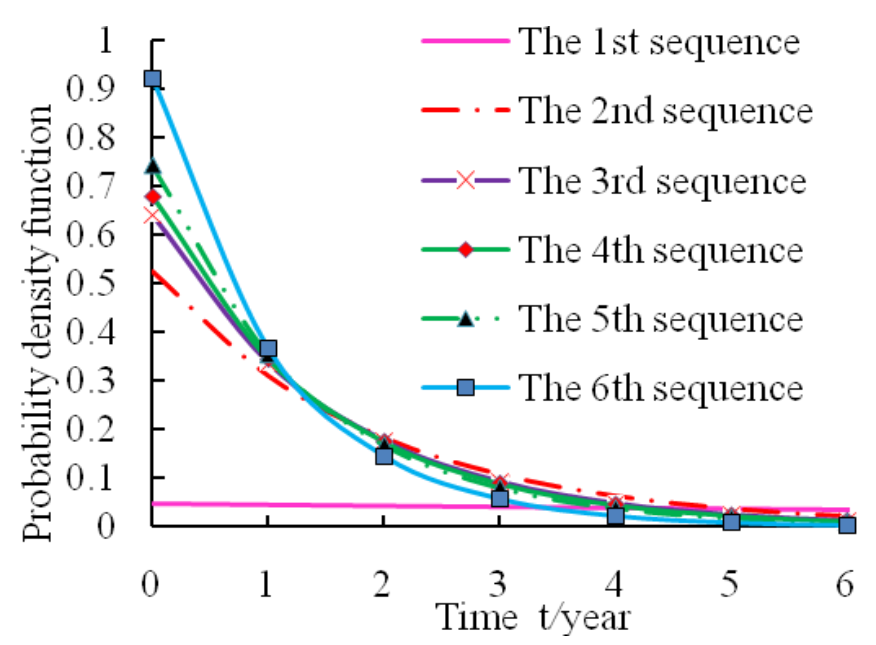

Figure 5. The probability density functions of time sequences

Table 4 The variation probabilities of sub sequences

\begin{tabular}{ccccc}
\hline $\begin{array}{c}\text { Order number of } \\
\text { sub sequences }\end{array}$ & $\begin{array}{c}\text { Wear } \\
\text { diameters }\end{array}$ & $\begin{array}{c}\text { Abscissas values of } \\
\text { intersection points } \\
n\end{array}$ & $\begin{array}{c}\text { Overlapped } \\
\text { areas }\end{array}$ & $\begin{array}{c}\text { Variation } \\
\text { probabilities }\end{array}$ \\
\hline 2 & 0.15 & 4.9878 & $S_{n}$ & $P_{n}$ \\
\hline 3 & 0.3 & 4.3491 & 0.2886 & 0.6914 \\
4 & 0.45 & 4.1774 & 0.2525 & 0.7475 \\
5 & 0.6 & 3.9059 & 0.2428 & 0.7572 \\
6 & 0.75 & 3.3668 & 0.2273 & 0.7727 \\
\hline
\end{tabular}

The relationship between variation probabilities and wear diameters is shown in Fig. 6.

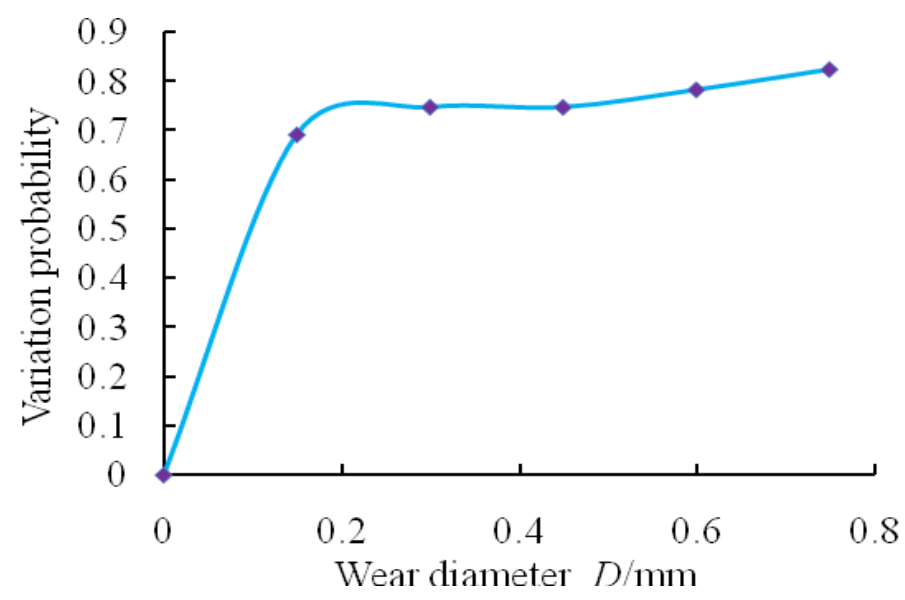

Figure 6. The variation probabilities of sub sequences

Fig. 6 shows that the variation probabilities increase with the increase of wear diameters, because the bearings vibrate more and more sharply and will fail finally. On the whole, the variation probability presents a nonlinear increase trend, which can be divided into three stages: from the rapid increase stage to the slowly increase and trace fluctuations stage, and then to the rapid increase stage. $P_{n}>0.8$ when the wear diameter $D=0.75 \mathrm{~mm}$, which shows that the variation of the vibration performance of bearings is serious. So the bearings should be maintained or replaced. 


\section{Summary}

The vibration acceleration data of rolling bearings (type SKF6205) is used as an example to illustrate the application of bootstrap maximum entropy theory in analyzing the variation process. The experimental investigation shows that the variation probabilities increase with the increase of wear diameters. Moreover, the maximum entropy grey bootstrap principle does not rely on any prior information about the possibility distribution of the performance data of rolling bearings, which can provide a scientific and reasonable supplement for available reliability assessment methods in evaluating the reliability variation process.

\section{Acknowledgements}

This project was funded by the National Natural Science Foundation of China (Grant Nos. 51475144 and 50375011).

\section{References}

[1] G. Jin. Performance Reliability modeling and estimation for space bearing under small sample circumstance. Journal of University of Defense Technology, 2010, 32(1): 133-137.

[2] W. Ouyang, F. Zhang and J.L. Wang, et al. Research on magnetic loading in reliability enhancement testing of low viscosity lubricated bearings. Journal of Mechanical Engineering, 2015, 51(4): 199-205.

[3] D.X. Zhu, H.Z. Liu and D.N. Yuan, et al. Time determination and life assessment of high-speed railway bearing reliability test. China Mechanical Engineering, 2014, 25(21): 2886-2890.

[4] X.T. Xia, B.M. Zhang and Y.Z. Xu. Variation Process Evaluation for Performance and Reliability of Rolling Bearing Using Poor Information Theory, first ed., Science Press, Beijing, 2013.

[5] X.C. Zhao, G.L Liu and H.Q. Liu, et al. Particle swarm optimization algorithm based on non-uniform mutation and multiple stages perturbation. Chinese Journal of Computers, 2014, 37(9): 2058-2069.

[6] Y.P. Wen and H.L. Shang. Analysis of performance variation for an indirect connection tuning-fork vibratory micro-gyroscope. Machinery Design and Manufacture, 2013, (7): 80-83.

[7] X.T. Xia, Y.Y. Meng and Ming Qiu, et al. Forecasting for variation process of reliability of rolling bearing vibration performance using grey bootstrap Poisson method. Journal of Mechanical Engineering, 2015, 51(9): 97-103.

[8] X.T. Xia, L. Ye and Z. Chang. Reliability evaluation theory for variation process of vibration performance of rolling bearings. 2016 International Conference on Electronic, Mechanical, Information and Management, 2016.

[9] H. Cao, X.H. Wang and F.Y. Mao, et al. Double-layer fuzzy synthetic evaluation model of the color comfort degree in industrial circumstance. Advanced Materials Research, 2012, (591-593): 2540-2544.

[10] X.C. Sun, X.T. Xia and Y.B. Liu, et al. Evaluation of rolling bearing vibration using fuzzy set theory and chaos theory. Advanced Materials Research, 2012, 424-425: 338-341.

[11]X.T. Xia, Y.Y. Qin and M. Qiu. Adjustment for the machining errors of machine tool based on grey bootstrap maximum entropy method. Journal of Mechanical Engineering, 2014, 9(17): 2273-2276. 